\title{
Thermal Analysis of Immersed Heat Source during Flow Reduction Transient
}

\author{
Akram W. Ahmed Ezzat, \\ Ph.D \\ Asst. Prof. Dept. of Mech. Eng. \\ University of Baghdad
}

\author{
Salah I. Hasan \\ Dept. of Mech. Eng. \\ University of Baghdad
}

\begin{abstract}
Theoretical and experimental study of transient heat transfer parameters related to downward flowing water in a circular concentric annular channel is conducted. The cooling channel is exposed internally to sinusoidal heat flux and has an adiabatic outer surface. The present theoretical study investigated the heat transfer and thermodynamic parameters during of $25 \%, 50 \%$, and $75 \%$ flow reduction transients. The related experiments to such flow reductions simulates the loss of flow accidents (LOFA) in the research nuclear reactors initiated by loss of main power supply, pump failure, heat exchanger blockage, pipe blockage or valve closing. The results of steady state condition set as an initial condition for the transient model which is evaluated by using M-fileMatlabR2013a written computer program. The theoretical transient approach involved a mathematical model based on the analytical solution for first order ordinary differential equations supported by experimental correlations for axially, symmetric, simultaneously developing laminar water flow in a vertical annulus cooling channel which takes under consideration the nucleate boiling, film boiling and two phase flow formulation. The mathematical model is based on one dimensional downward flow. Unit step flow reduction function is implemented in the present model to simulate the flow reduction transient. It is noteworthy that the unit step reduction function is used first time in the recent study among the related previous study. The present experimental investigation included a set of experiments carried out to investigate the thermal-hydraulic behavior and evaluate their boiling safety factor, $\mathrm{K}$. The present work is based on the following initial and boundary conditions: heat flux of 50 $\mathrm{kW} / \mathrm{m}^{2}$, mass flux values of $192.6,128.4$, and $64.2 \mathrm{~kg} / \mathrm{m}^{2} . \mathrm{s}$ to simulate the $25 \%, 50 \%$ and $75 \%$ flow reduction transients as the nominal mass flux is $256.8 \mathrm{~kg} / \mathrm{m}^{2}$.s accompanied with keeping the inlet cooling water pressure around 1.06 bar, inlet water temperature equal $80^{\circ} \mathrm{C}$ and $\frac{\mathrm{L}}{\mathrm{D}}=38.89$. Before initiating the flow reduction transient scenario, the acceptable thermalhydraulic safety level of the cooling system is set to be close from the acceptance criteria $(K \geq 1.6)$ that implemented in the Iraqi nuclear reactor $\left(14^{\text {th }}\right.$ Tammuz $5000 \mathrm{~kW}$ Reactor $)$ referred to the final safety analysis report that done by (A.W.Ezzat and H.M.Taki, 1988). It is concluded that $\mathrm{K}$ value reaches around unity for $25 \%$ and $50 \%$ of flow reduction percentage transient at around 5 and 3 seconds respectively from transient initiation while the $\mathrm{K}$ value dropped below the unity at $75 \%$ of flow reduction transient. The surface dry out takes place during $75 \%$ and $100 \%$ flow reduction at normalized distance of 0.65 away from the cooling channel entrance based on experimental observation due to the onset of flow instability (OFI) that encounter the downward flow direction at low pressure and low velocity system (LPLV). It's also conclude that the elapsed time required for the surface temperature to reach its steady state values after each transient scenario is less than that related to bulk water temperature as long as the
\end{abstract}

water temperature kept below its saturation temperature. Generally, the present experimental and theoretical results showed good agreements.

\section{Keywords}

Loss of flow accident, Dry out, Nucleate boiling and film boiling, Heat transfer parameters, Downward flow, circular concentric annular channel, Two phase flow, Onset of flow instability.

\section{INTRODUCTION}

The main objective for reactor safety is to keep the fuel in a thermally safe condition with adequate safety margins during all operation modes (normal, abnormal and accidental states). To achieve this purpose an accident analysis of different design base accident (DBA) as a loss of flow accident (LOFA), is required for assessing reactor safety. LOFA is one of frequently occurring DBA with most severe consequences among others. In transient simulations, it is customary to consider the situation with or without scram event, called protected and unprotected transients. It affects fuel integrity due to its overheating resulting from a low coolant heat transfer coefficient and consequently low cooling ability for reactor core. However, the primary core cooling system (PCCS) should assure core cooling and provide an adequate safety margin to critical phenomena as a departure from nucleate boiling (DNB) due to loss of off-site power, pump failure, heat exchanger blockage, pipe blockage or valve closing [1].The effect of flow reduction, pressure reduction or heat power increase transients in power generated system is studied thoroughly to explain its practical significance in flow boiling systems, see figure (1). Several theoretical and experimental works are related to the present study. Ahmed Mohammed El-Messiry, 2000 [1] investigated the thermal behavior of Egypt test and research reactor ETRR-2 during loss of flow accident (LOFA). He developed an accident analysis code (FLOWTER) for his study. The active core is simulated by two channels: 1- hot channel (HC), and 2average channel (AC) representing the remainder of the core. He divided each channel into four axial sections. The external loop, core plenums, and core chimney were simulated by different dynamic lumps. The code includes modules for pump coast down, flow regimes, decay heat, temperature distributions, and feedback coefficients. His study indicated that for LOFA transient, provided the scram system is available, the core shutdown safely by low flow signal (496.6 $\mathrm{kg} / \mathrm{s}$ ) at $1.4 \mathrm{~s}$ where the $\mathrm{HC}$ temperature reaches the maximum value of $45.64^{\circ} \mathrm{C}$ after shutdown. On the other hand, if the scram system is unavailable, and $t=47.33 \mathrm{~s}$, the core flow decrease to $67.41 \mathrm{~kg} / \mathrm{s}$, and the $\mathrm{HC}$ clad surface heat flux exceeded its critical value of $400 \mathrm{~W} / \mathrm{cm}^{2}$ resulting of fuel burnout. 


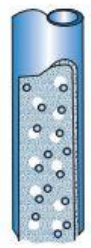

(a) Bubble

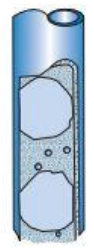

(b) Slug (c) Annular

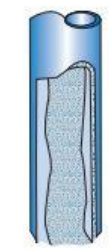

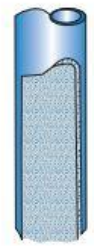

(d) Mist

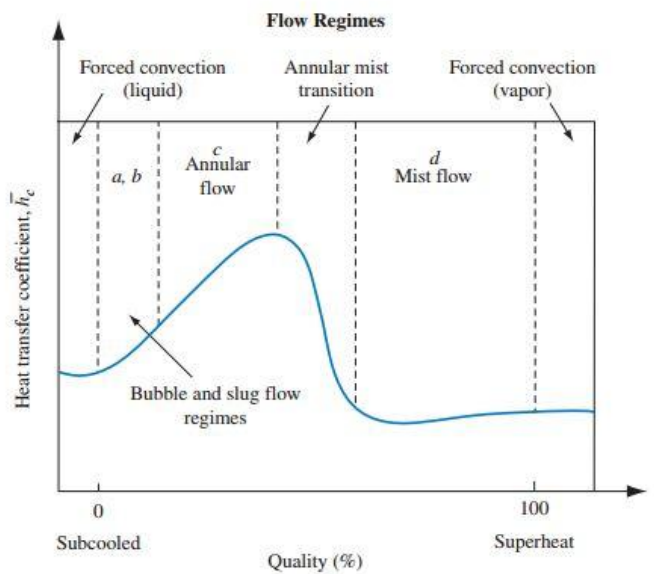

Figure (1): Heat transfer coefficient versus quality and types of flow regime.

Qing Lu et al. 2009 [2], investigated the course of the partial and total blockage of a channel in the IAEA 10 MW MTR pool type research reactor core without scram. The analysis was performed with best estimate code RELAP5/MOD3.3. The interaction of the obstruction channel and its adjacent channels has been taken into account. The results indicated that even when the flow channel has been totally blocked, there is still no boiling occurrence, and the fuel temperature is low enough to maintain its integrity. Hainoun et al. 2010 [3], used the thermal hydraulic code MERSAT, (Model for Evaluation of Reactor Safety and Analysis of Thermal hydraulic) in his study. Detailed model including primary and secondary loop was developed for the International Atomic Energy Agency, IAEA reference research reactor material MTR 10MW. The developed model enables the simulation of expected neutronic and thermal hydraulic phenomena during normal operation, reactivity and loss of flow accidents. They found that two different losses of flow accident have been simulated using slow and fast decrease time of core mass flow rate. In both cases the expected flow reversal from downward forced to upward natural circulation has been successfully simulated. His results indicated that in accidents the limit of onset of sub-cooled boiling was not arrived and consequently no exceed of design limits in term of thermal hydraulic instability or DNB is observed. Hong Gao and Xuewu Cao 2011[4], developed a mathematical model for solving flow rate transient and pump speed transient during flow coast down period. The flow rate and pump speed solved analytically. The calculated non-dimensional flow rate and non-dimensional pump speed using the model compared with published experimental data of two nuclear power plants and a reactor model test on flow coast down transient. The comparison results showed a good agreement. As the flow rate approaches to zero, the difference between experimental and calculated values increases due to the effect of mechanical friction loss. A.D. Vasiliev et. al 2012 [5] simulated a severe LOCA (loss of coolant accident) in NPP (nuclear power plant) sequence in which the overheated core up to $1700-2300 \mathrm{k}$ would be re- flooded from the bottom on ECCS (emergency cooling core system) recovery. After maximum cladding temperature of about $1900 \mathrm{k}$ had been reached in the bundle during PARAMETER-SF4 (the name of facility) test, bottom flooding was initiated. The thermal hydraulic and SFD (severe fuel damage) best estimate computer modeling code (SOCRAT/V2) was used for the calculation of PARAMETERSF4 experiment. The important feature of PARAMETER-SF4 was the air ingress phase and the thermal hydraulic behavior during the reflood. The adequate modeling of thermal hydraulic and chemical phenomena that occurred during the test, including the convective and radiative heat transfer in the bundle, the oxidation during the air ingress phase and the two phase coolant behavior during the bottom reflood, has allowed to calculate the correct thermal behavior in the test.

\section{EXPERIMENTAL WORK}

Proper heat source is designed in order to impart sinusoidal heat flux that used to heat up the flowing water in vertical downward direction in annulus that surround it, the test section shown in the schematic diagram of figure (2).

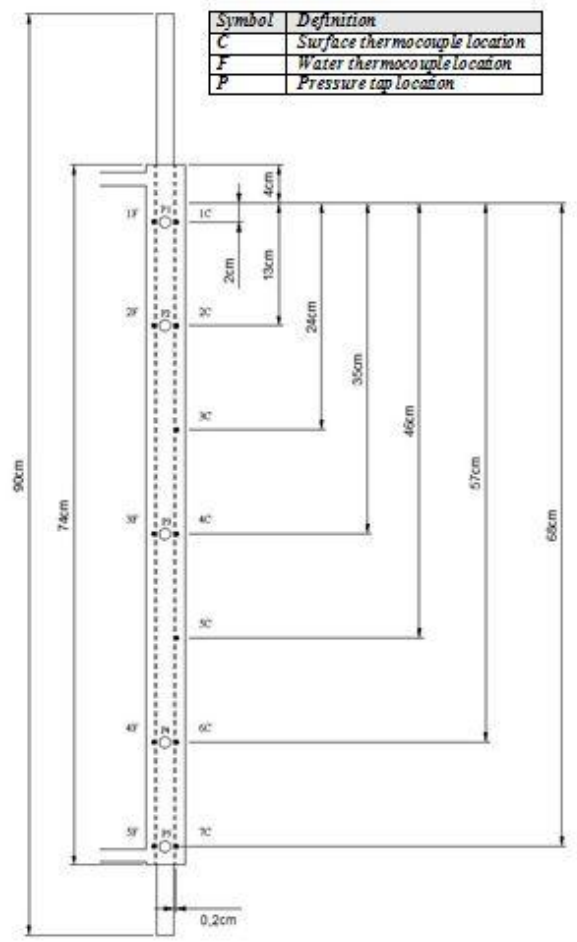

Figure (2): Test section schematic diagram.

The heat source consists of nickel-chrome wire is divided into 9 connected sub segments symmetrically in different wire resistance value in order to generate sinusoidal axial heat flux distribution, wounded as (O) shape coil surrounded by hollow ceramic discs inside stainless steel tube, in the ends of the coil two studs are connected to be its electrical terminals and the stainless steel tube is fitted with thermal cement to isolate this coil from the stainless steel tube as shown in figure (3a) and figure (3b).

Figure (3a): Electrical heater wire wraps. 


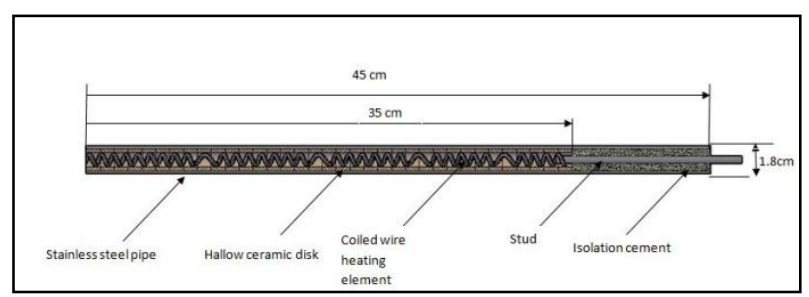

Figure (3b): Half of symmetrical heat source parts.

The curve fitting tool of MatLabR2013a used to find the heat flux distribution expression as shown in figure (4) and given;

$$
\begin{aligned}
q_{z(i)}=q_{t o t} \cdot\left[\left(a 1 \sin \left(b 1 z_{(i)}+c 1\right)\right.\right. \\
+\left(a 2 \sin \left(b 2 z_{(i)}+c 2\right)\right]
\end{aligned}
$$

Where,

$\mathrm{z}_{\mathrm{i}=} \mathrm{Z}_{\mathrm{i}} / \mathrm{L}, \mathrm{a}_{1}=0.2509, \mathrm{a}_{2}=0.0837, \mathrm{~b}_{1}=\mathbf{2 . 9 3 4}, \mathrm{b}_{2}=4.895$,

$c_{1}=0.1226, c_{2}=2.231$

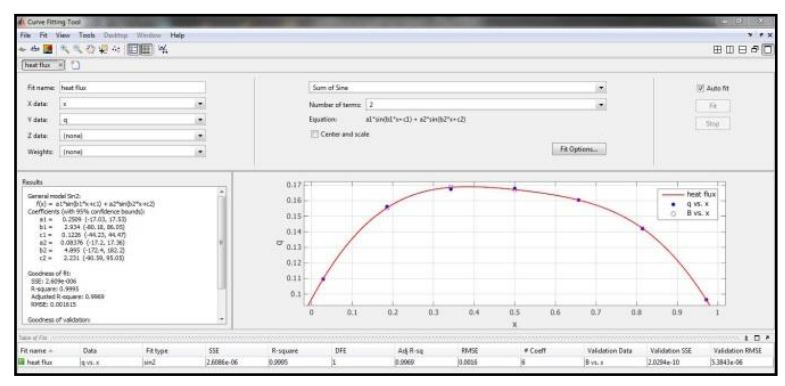

Figure (4): Curve fitting for sinusoidal heat flux profile.

The schematic diagram of the test rig is shown in figure (5), the length of the heater is $(90 \mathrm{~cm})$, while it's heating active length is $(70 \mathrm{~cm})$, the diameter is $(1.8 \mathrm{~cm})$, the maximum total power is $3000 \mathrm{~W}$, resistance of heat source $(16.133 \Omega)$ and the maximum applied voltage (180220) Volt. The flowing channel is made of Teflon to minimize the heat lost to the surrounding air due to its low thermal conductivity $(0.19-0.25 \mathrm{~W} / \mathrm{m} . \mathrm{K})$ in addition to its suitable melting point $\left(260-327^{\circ} \mathrm{C}\right)$ to withstand the water temperature of the flow patterns during water phase change. The cylindrical channel thickness is $(1 \mathrm{~cm})$, its length is $(75 \mathrm{~cm})$, with inner diameter equals $(2.2 \mathrm{~cm})$ and outer diameter equals $(4.2 \mathrm{~cm})$. The cylindrical channel is insulated by glass fibers sheath. To ensure the gap between two concentric cylinders equal to $(0.2 \mathrm{~cm})$, proper flanges made from Teflon are fitted in the both ends of the cylindrical channel to resist the high temperature caused by the effect of the heat source in the top and bottom of the annular channel. The temperature of the outside surface of the tube heat source is measured by using seventh alumel-chromel (type K) thermocouples installed in seven spaces $(2,13,24,35,46,57$, and 68) $\mathrm{cm}$ arranged along the heated wall. The end of thermocouple wires connected with standard male plug in order to connect them with the digital thermometer. Circular holes of $(\mathrm{d}=1.27 \mathrm{~cm})$ are drilled in the surface of the Teflon cylinder to provide a proper space for thermocouples welding operation on the tube surface, these holes are sealed by drilled pipe end plugs of $(\mathrm{d}=1.27 \mathrm{~cm})$ to pass the thermocouple wires through them and then covered by special epoxy that withstands $200{ }^{\circ} \mathrm{C}$. The thermocouples are installed in equal space distances at seven positions.

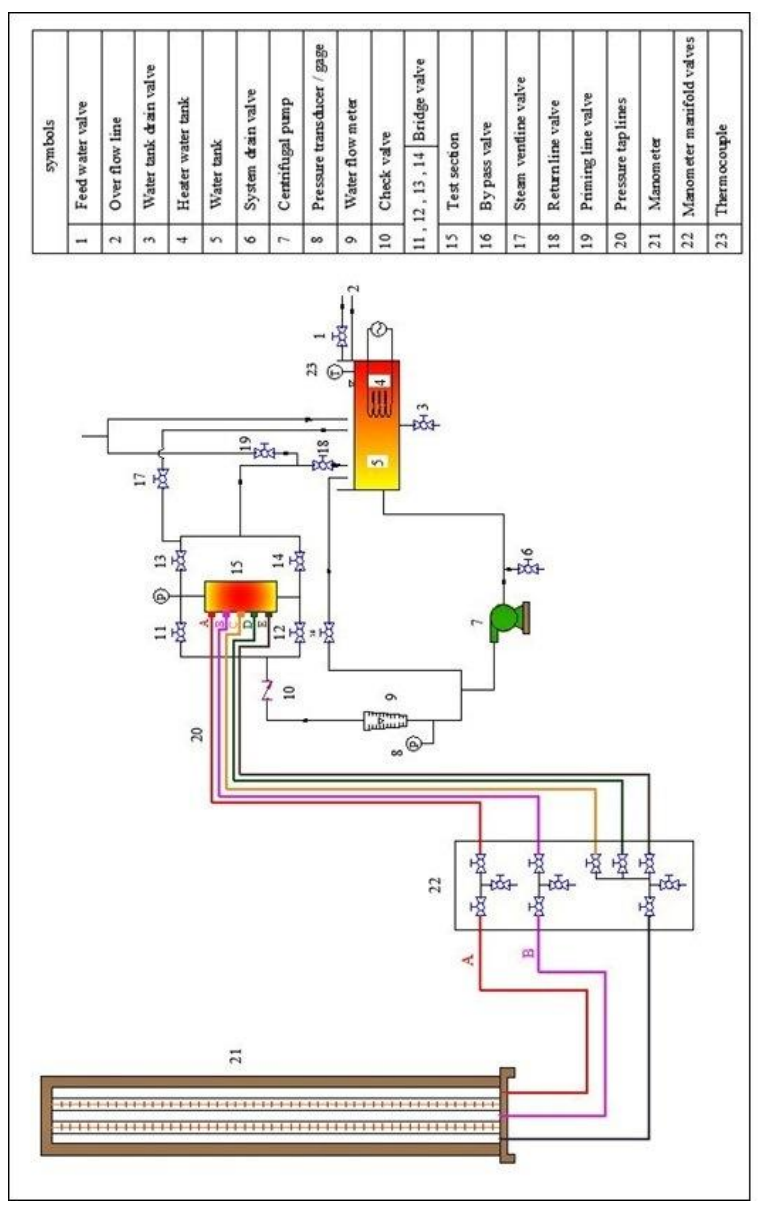

Figure (5): Test rig schematic diagram.

The supplied water to the annular test section is heated up to $\left(80^{\circ} \mathrm{C}\right)$ in a rectangular cross section tank of $(40 \times 30 \times 30) \mathrm{cm}$ dimensions by electrical heater of 3000 $\mathrm{W}$. The tank is shown photographically in plates (1).

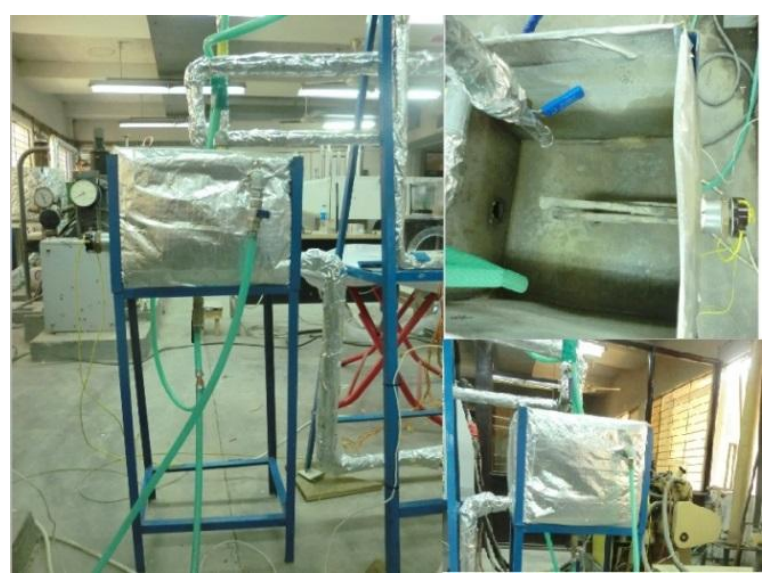

Plate (1): Water tank of the test rig.

The water desired temperature in the tank, $80{ }^{\circ} \mathrm{C}$ controlled by adding cold water through line 1 and dump the hot water from valve 3 . A check valve is connected directly before the pipes bridge to prevent water back flow from the test section to the water tank and to ensure that entire heater length is covered by water during conducting 
$100 \%$ of flow reduction tests and serve as pressure drop element to stabilize the cooling flow and avoiding the backflow phenomena, see plate (2).

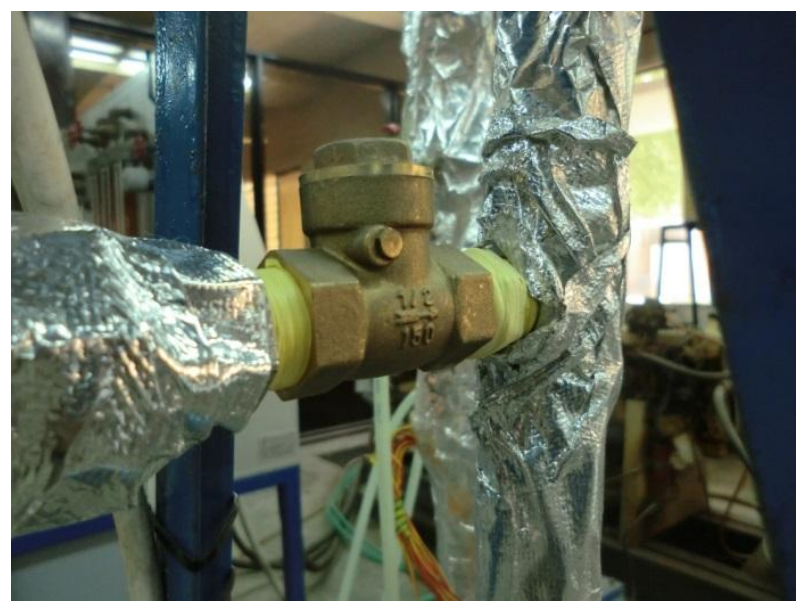

Plate (2): Check valve connected directly before the pipes bridge.

The positions of the control valve are marked in three locations that represent particular flow reduction $(25 \%$, $50 \%$, and $75 \%$ from its nominal value) to ensure accurate step reduction change in the volumetric water flow rate during conducting coolant fluid reduction tests, see plate (3).

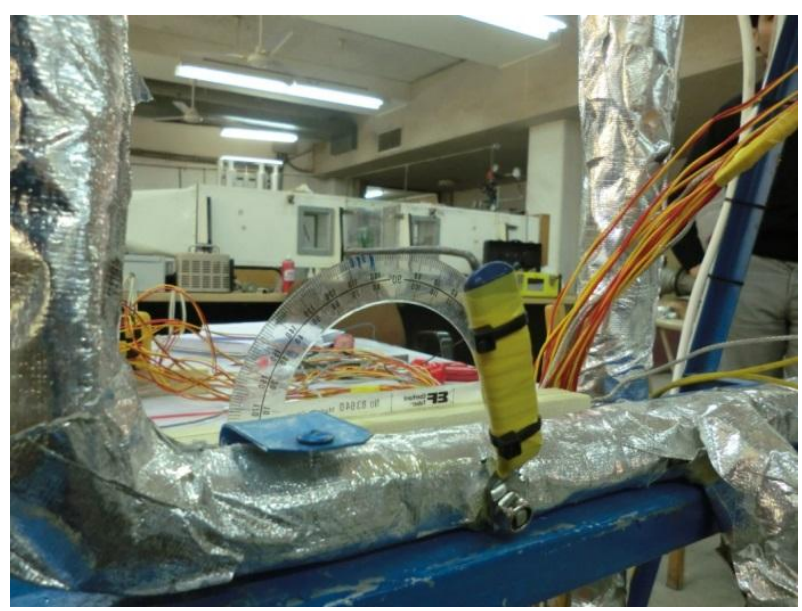

Plate (3): Downward flow outlet control valve.

The feed pipe contains of a flow meter (0.5-4 LPM) to read water flow rate in the test section channel, see plate (4). A pressure gage of (0-100 $\mathrm{kPa}$.) range is used to measure the inlet pressure of the cooling water. The pressure through the annular channel measured by manometer manufactured locally, as shown in plate (5).

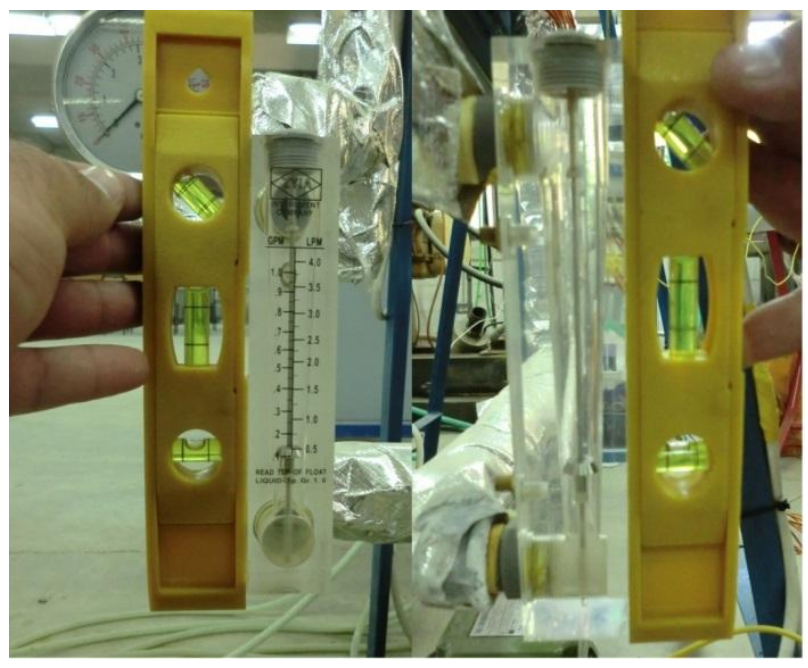

Plate (4): Water flow meter.

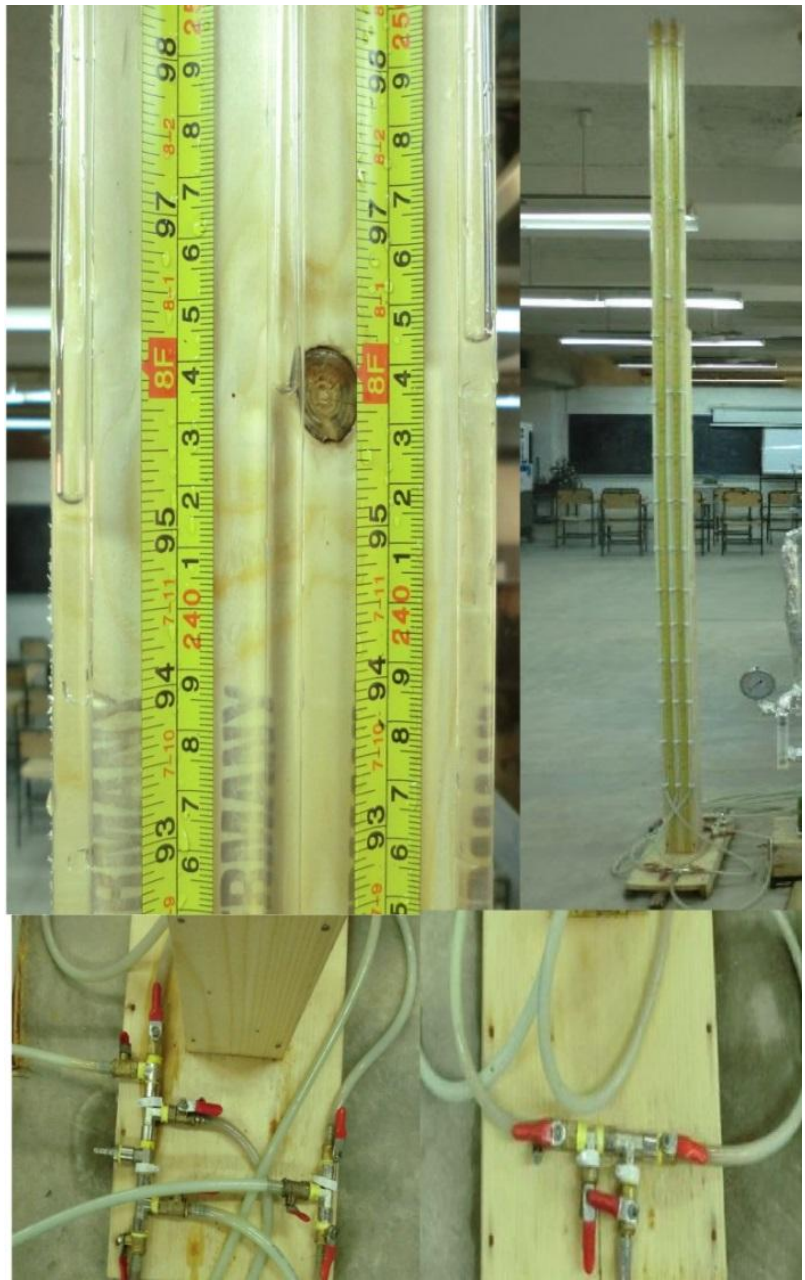

Plate (5): Manometer components.

During initiate the flow reduction scenarios the pressure transient heads recorded by a digital Camera and the heat source surface temperature and cooling water temperature recorded by 12 channel temperature data logger. The measurements devices that used in the present conducted tests are shown in plate (6). 


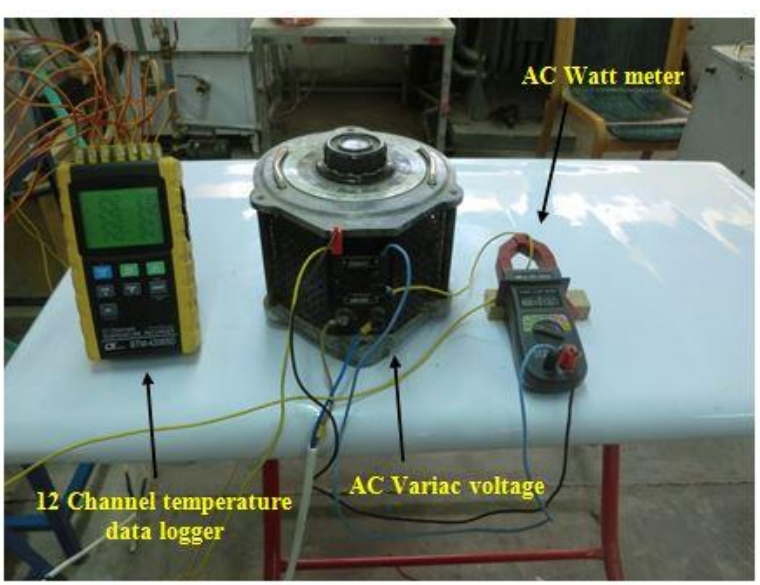

Plate (6): Measurement devises.

The electrical circuit diagram of the test rig is shown in

figure (6).

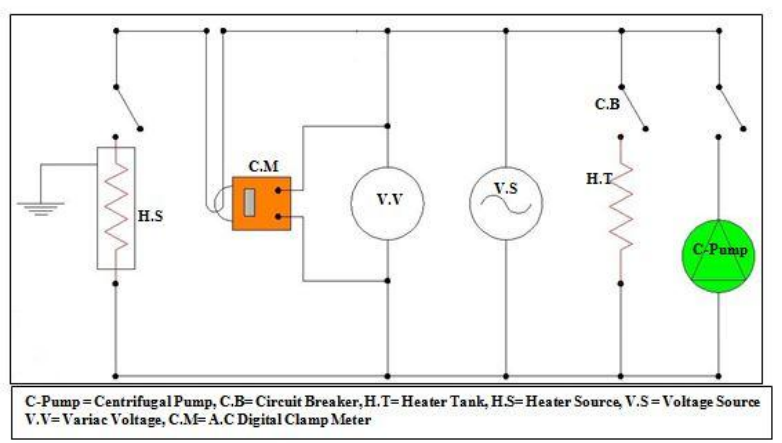

Figure (6): Electrical circuit diagram of the test

rig.

\section{THEORETICAL ANALYSIS}

Flowing water in a vertical annulus subjected to transient forced convection effect in radial direction is presented for modeling. A one- dimensional model could be used to describe the transient forced convection heat transfer in a vertical annulus, with inner radius $r_{i}$ and outer radius $r_{0}$. Water flow direction is assumed to be in the downward direction according to the experimental setup. The following assumptions are used in the modeling:

- Incompressible fluid.

- One dimensional in (z-axis) flow. There is only one non zero velocity component, namely that in the direction of flow, $v_{\mathrm{z}_{\text {, }}}$ thus, $\mathrm{v}_{\mathrm{r}}=\mathrm{v}_{\theta}=0$.

- The axial velocity is independent of the angular location; that is, $\frac{\partial w_{z}}{\partial \theta} 0$.

- Simultaneously developing hydrodynamic.

- No internal heat generation and heat dissipation.

- Neglecting viscous dissipation.

- Variable fluid properties versus its temperature $\left(\rho, \mu, k, C_{P}\right)$.

- The flow during steady state condition is single phase as water bulk temperature does not exceed the saturation temperature along the cooling channel, $\mathrm{x}=0$.
The two phase flow and heat transfer during transient case at the upper part of the test section where water quality, $x>0$ is based on homogeneous model.

\subsection{Formulas Used for Prediction Measured Parameters during Steady State Condition.}

To analyze the heat transfer process by forced convection from the heat source surface to the liquid water flowing along it through annular section adjacent to the heat source surface simplified steps were used by conducting mass and heat balance at specified cross sectional area in the channel. The heat transfer coefficient is one of the affective parameters that should be estimated using the proper correlation, Calculation procedure is conducted as follows:

- The total input power supplied to the heat source can be calculated as;

$Q_{\text {tot. }}=$ Watt meter reading $(W)$

- Total heat flux $\left(\mathrm{W} / \mathrm{m}^{2}\right)$ is calculated by using the following relation;

$q_{\text {tot. }}=\frac{Q_{\text {tot. }}}{A_{s}}$

$A_{s}=\pi \cdot d_{i} \cdot L$

- The cross section area $\left(\mathrm{m}^{2}\right)$ of annular tubes, in which the cooling water flowing inside it could be calculated as follows:

$$
A_{\mathrm{f}}=\frac{\pi}{4}\left(\mathrm{~d}_{0}^{2}-\mathrm{d}_{1}^{2}\right)
$$

- The average cooling water velocity $(\mathrm{m} / \mathrm{s})$ of water could be determined as follows:

$$
v=\frac{Q^{o}}{A_{f}}
$$

- To determine bulk water temperature at specified points and compare them with the four thermocouple read out fixed along the gap between heater wall and cooling channel wall during steady state condition, the following equation is derived for prediction it, the results of heat balance can express as;

$$
\begin{array}{r}
T_{b(i+1)=T_{b i}+\frac{Q_{t o t .}}{m^{o} c_{p}}[}\left(a 1 \sin \left(b 1 z_{(i+1)}+c 1\right)+\right. \\
\left(a 2 \sin \left(b 2 z_{(i+1)}+c 2\right)\right]
\end{array}
$$

- Dependence of local Nusselt number on the distance could be written in the following form according to Petukhov, 1986 ; [A.D. Vasiliev et. al 2012]. 
$N u(Z)$

$$
= \begin{cases}1.31\left[\frac{Z}{P e . D_{h}}\right]^{-\frac{1}{3}} & \frac{Z}{P e . D_{h}} \leq 0.001 \\ 4.36+1.31\left[\frac{Z}{\text { Pe. } D_{h}}\right]^{-\frac{1}{3}} \cdot e^{\left(-13 \sqrt{\frac{Z}{P e . D_{h}}}\right),} & \frac{Z}{P e . D_{h}}>0.001 \\ \ldots \ldots . . .(7)\end{cases}
$$

Where;

$$
\begin{aligned}
& P e=R e \cdot P r \\
& R e=\frac{\rho \cdot v \cdot D_{h}}{\mu} \\
& P r=\frac{\mu C_{p}}{k}
\end{aligned}
$$

Thus, the local convective heat transfer coefficient $\left(h_{c}\right)$ could be evaluated as following;

$$
h_{c}=\frac{N u_{Z} \cdot k}{D_{h}}
$$

To obtain the local heat transfer coefficient it is necessary to calculate the film temperature as shown below:

$T_{f(i)}=\frac{T_{s(i)}+T_{b(i)}}{2}$

Where $\left(\boldsymbol{C}_{\boldsymbol{p}}, \boldsymbol{\rho}, \boldsymbol{\mu}, \boldsymbol{k}\right)=\boldsymbol{f}\left(\boldsymbol{T}_{\boldsymbol{f}}\right)$

- The heat source surface temperature is calculated by using the following formula:

$$
\begin{aligned}
T_{s(i)}=T_{b(i)} & \\
+\frac{q_{t o t}}{h_{c_{i}}}[ & \left(a 1 \sin \left(b 1 z_{(i)}+c 1\right)\right. \\
& +\left(a 2 \sin \left(b 2 z_{(i)}+c 2\right)\right]
\end{aligned}
$$

\subsection{Derivation of Temperature Response to Flow Reduction Transient According to Step Disturbance Function}

The derivation of bulk water and surface temperature to flow step reduction is based on the single phase flow (Liquid) and two phase flow (Liquid-Steam) along the cooling channel. The temperature response could be derived from the heat balance as shown in figure (7a) and (7b).

Heat balance for cooling water element;

$$
\begin{aligned}
& Q_{\text {in }}+Q_{g e n}=Q_{\text {stored }}+Q_{o u t} \\
& Q_{i}+m_{r}^{0} C_{p_{l}} T_{s t(i)}-m_{r}^{0} C_{p_{l}} T_{t(i)}=M C_{p_{l}} \frac{d T_{a v(i)}}{d t}
\end{aligned}
$$

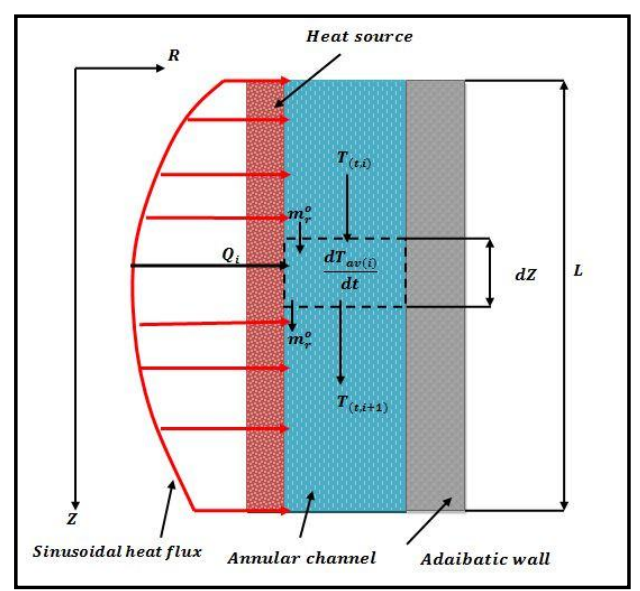

Figure(7a): Heat balance for cooling water element

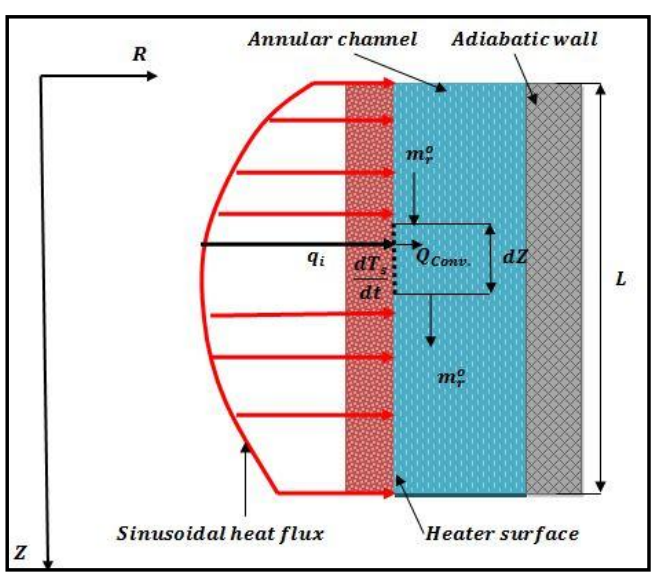

Figure(7b): Heat balance for heat source surface element

$$
\begin{gathered}
T_{a v(i)}=\frac{T_{s t(i)}+T_{b(t, i)}}{2} \rightarrow \\
T_{b(t, i)}=2 T_{a v(i)}-T_{s t(i)}
\end{gathered}
$$

After substituting equation (15) in equation (14) to get ;

$$
\frac{M}{m_{r}^{0}} \frac{d T_{a v(i)}}{d t}+2 T_{a v(i)}=\frac{Q_{i}}{m_{r}^{0} C_{p_{l}}}+2 T_{s t(i)}
$$

By solving equation (16) using the integration factor method and applying the initial condition $\mathrm{T}_{\mathrm{av}(0, \mathrm{i})}=\mathrm{T}_{\mathrm{st}(\mathrm{i})}$ to find the following,

$$
\begin{aligned}
T_{a v(t, i)}=T_{s t(i)} e^{-\left(2 \frac{m_{r}^{0}}{M}\right) t} & \\
& +e^{-\left(2 \frac{m_{r}^{0}}{M}\right) t}\left(e^{-\left(2 \frac{m_{r}^{0}}{M}\right) t}-1\right)\left(\frac{Q_{(i)}}{2 m_{r}^{0} C_{p_{l}}}\right. \\
& \left.+T_{s t(i)}\right)
\end{aligned}
$$


To obtain the water single phase flow (liquid phase) transient temperature value for $\mathrm{T}_{\mathrm{b}(\mathrm{t}, \mathrm{i})}$ substitute the results of equation (17) in equation (15).

In case of two phase flow (water liquid -steam) take place, the water temperature may be obtained by;

$$
\begin{aligned}
& T_{b(t, i)}=T_{s a t(t, i)} \\
& T_{s a t(t, i)}=f\left(P_{t p(t, i)}\right)
\end{aligned}
$$

The surface heater temperature during transient condition at any section of the surface heater length at any time could be derived from the following heat balance:

$Q_{(i)}=Q_{c o n v .}+M_{S} C_{p_{S}} \frac{d T_{s(i)}}{d t}$

$M_{S} C_{p_{S}} \frac{d T_{s(i)}}{d t}=Q_{(i)}-h_{(i)} A_{s(i)}\left(T_{s(i)}-T_{b(i)}\right)$

Divide both equation side by $\left(h_{(i)} A_{s(i)}\right)$ to get the following;

$$
\frac{M_{S} C_{p_{S}}}{h_{(i)} A_{s(i)}} \frac{d T_{s(i)}}{d t}+T_{s(i)}=T_{b(i)}+\frac{q_{(i)}}{h_{(i)}}
$$

By solving equation (19) using integration factor method and applying the initial condition $\mathrm{T}_{\mathrm{s}(0, \mathrm{i})}=\mathrm{T}_{\mathrm{st}(\mathrm{i})}$ to find the following;

$$
\begin{aligned}
T_{s(t, i)}=T_{b(t, i)}+\frac{q_{(i)}}{h_{(t, i)}} & \\
- & {\left[e ^ { - ( \frac { h _ { i ( t ) } A _ { s ( i ) } } { M _ { S } C _ { p _ { S } } } t ) } \left(T_{b(t, i)}+\frac{q_{(i)}}{h_{(t, i)}}\right.\right.} \\
- & \left.\left.T_{s(s t(i))}\right)\right]
\end{aligned}
$$

For single phase (liquid) flow $\left(\mathrm{T}_{\mathrm{s}}<\mathrm{T}_{\mathrm{B}}\right.$ and $\mathrm{T}_{\mathrm{b}}<\mathrm{T}_{\text {sat }}$ ), equation (11) is used to evaluate the heat transfer coefficient. In the sub cooled nucleate boiling regime $\left(\mathrm{T}_{\mathrm{s}} \geq \mathrm{T}_{\mathrm{B}}\right.$ and $\mathrm{T}_{\mathrm{b}}<\mathrm{T}_{\text {sat. }}$ ) the proposed correlation by Chen (Frank Kreith2011, [7] ) is used which could be expressed as following;

$h_{N B}=F h_{c}+S h_{b}$

Where;

$\mathrm{h}_{\mathrm{c}}=$ Convective heat transfer coefficient $\left(\mathrm{W} / \mathrm{m}^{2}{ }^{\circ} \mathrm{C}\right)$ equation (11) is based on the following expression of Reynolds number:

$$
\begin{aligned}
& R e=\frac{G(1-x) D_{h}}{\mu_{l}}(22) \\
& h_{b}=0.00122\left(\frac{k_{l}^{0.79} C_{p l}^{0.45} \rho_{l}^{0.49} g^{0.25}}{\sigma^{0.5} \mu_{l}^{0.29} h_{l g}^{0.24} \rho_{v}^{0.24}}\right) \Delta T_{x}^{0.24} \Delta p_{s a t}^{0.25}
\end{aligned}
$$

The parameter $F$ could be calculated from

$$
F=\left\{\begin{array}{lr}
1, & \text { When } \frac{1}{X_{t t}}<1 \\
2.35\left(\frac{1}{X_{t t}}+0.213\right)^{0.736}, \text { When } \frac{1}{X_{t t}}>1
\end{array}\right.
$$

The parameter $S$ is given by;

$S$

$$
=\left\{\begin{array}{lr}
\left(1+0.12 \operatorname{Re}_{T P}^{1.14}\right)^{-1}, & \text { for } \operatorname{Re}_{T P}<32.5 \\
\left(1+0.42 \operatorname{Re}_{T P}^{0.78}\right)^{-1}, & \text { for } 32.5<\operatorname{Re}_{T P}<70 \\
0.1, & \text { for } \operatorname{Re}_{T P}>70
\end{array}\right.
$$

With Reynolds number $R e_{T P}$ defined as;

$R e_{T P}=\frac{G(1-x) D_{h}}{\mu_{l}} F^{1.25} 10^{-4}$

For film boiling $\left(\mathrm{T}_{\mathrm{b}}=\mathrm{T}_{\mathrm{sat}}\right)$ region, the Bromley correlation is recommended and expressed as follows:

$\boldsymbol{h}_{F B}$

$=0.62\left[\frac{g\left(\rho_{l}-\rho_{v}\right) \rho_{v} k_{v}^{3}\left[h_{l g}+0.68 C_{p v}\left(T_{w a l l}-T_{b}\right)\right]}{D_{h} \mu_{v}\left(T_{w a l l}-T_{b}\right)}\right]^{0.25}$

\subsection{Sub-cooled Boiling Temperature and Boiling Safety Factor Estimation}

Sub-cooled nucleate boiling of the coolant starts when the heat source clad surface temperature reach to the boiling temperature $\left(\mathrm{T}_{\mathrm{B}}\right)$ at that position. The following correlation is used for $T_{B}$ estimation, [6].

$\boldsymbol{T}_{B}=\boldsymbol{T}_{\text {sat. }}+2.03 *{q_{z}}^{0.35} * \boldsymbol{p}^{-0.23}$

Where, $\mathrm{p}$ in bar. $\mathrm{T}_{\text {sat. }}$ in $\left({ }^{\circ} \mathrm{C}\right)$, and $\mathrm{q}_{\mathrm{z}}$ in $\left(\mathrm{kW} / \mathrm{m}^{2}\right)$.

To calculate the local static pressure (p) for single phase (liquid) flow the following equations could be used;

$p_{s p(i)}=p_{\text {in }}+p_{\text {stat }(i)}-p_{f r(i)}$

$p_{\text {stat }(i)}=\rho_{f(i)} g Z_{i}$

$p_{f r(i)}=f\left(\frac{Z_{i} v_{i}^{2}}{2 g D_{h}}\right)$

$\boldsymbol{f}=\frac{\mathbf{6 4}}{\boldsymbol{R e}} ;$ for smooth pipes and laminar flow

In case of two phase flow (water-steam) the local static pressure could be obtained from the following equations;

$p_{t p(i)}=p_{i n}+p_{S T A T(i)}-p_{m o m(i)}-p_{F R(i)}$ 
$p_{S T A T(i)}=\rho_{H(i)} * g * Z_{i}$

$\rho_{H(i)}=\rho_{l(i)}\left(1-\alpha_{i}\right)+\rho_{g} * \alpha_{(i)}$

Zivi's (1964) equation is used to evaluate the void fraction $(\boldsymbol{\alpha})$ as the following;

$$
\begin{aligned}
\alpha_{(i)}=\left[1+\frac{1-x_{i}}{x_{i}}\left(\frac{\rho_{g(i)}}{\rho_{l(i)}}\right)^{\frac{2}{3}}\right]^{-1} & (36) \\
P_{\text {mom }(i)}=G_{t o t}{ }^{2} & {\left[\left(\frac{1-x_{i}}{\rho_{l(i)}\left(1-\alpha_{i}\right)}\right.\right.} \\
& \left.+\frac{x_{i}^{2}}{\rho_{g(i)} \alpha_{i}}\right)^{2}-\left(\frac{1-x_{i}}{\rho_{l(i)}\left(1-\alpha_{i}\right)}\right. \\
& \left.\left.+\frac{x_{i}^{2}}{\rho_{g(i)} \alpha_{i}}\right)_{\text {in }}^{2}\right]
\end{aligned}
$$

In order to calculate the friction pressure drop in two phase flow, the method of Lockhart and Martinelli (1949) for Re < 4000 is used as follows:

$$
\begin{aligned}
& p_{F R}=\Phi_{\mathrm{gtt}(\mathrm{i})}^{2} \Delta p_{g(i)} \\
& \Delta p_{g(i)}=\frac{4 f_{g(i)} Z_{i} x_{i}^{2} G_{t o t(i)}^{2}}{2 D_{h} \rho_{g(i)}} \\
& f_{g}=\frac{64}{x R e}(39) \\
& \Phi_{\mathrm{gtt}}^{2}=1+5 X_{t t}+X_{t t}^{2} \quad(41) \\
& X_{t t(i)}=\left(\frac{1-x_{i}}{x_{i}}\right)^{0.9}\left(\frac{\rho_{g(i)}}{\rho_{l(i)}}\right)^{0.5}\left(\frac{\mu_{l(i)}}{\mu_{g(i)}}\right)^{0.1}
\end{aligned}
$$

To avoid sub-cooled nucleate boiling at clad surface, the maximum clad temperature at the hot spot should be lower than boiling temperature. A boiling safety factor $(\mathrm{K})$ given by the following equation is used to estimate this temperature;[6].

$K=\frac{T_{B}-T_{i n}}{T_{S}-T_{i n}}$

It's clear from equation (43) that the thermal-hydraulic cooling system will stay in the safe operation condition as long as $\mathrm{K}$ value above 1 .

\section{RESULT AND DISCUSSION}

Generally, the variation of the temperature along the heat source surface may be affected by many variables such as the local heat flux, water inlet temperature, water flow direction at low pressure low velocity system, water velocity inside the channel, gap between concentric cylinders and the distances of the test section at which the clad temperature is measured or calculated. Figures 8, 9, and 10 show the theoretical and experimental results of the thermal-hydraulic parameter $\left(\mathrm{T}_{\mathrm{s}}\right.$, $\mathrm{T}_{\mathrm{b}}$, and $\mathrm{K}$ respectively) during steady state condition and at total heat flux equal to $\left(50 \mathrm{~kW} / \mathrm{m}^{2}\right)$, inlet water temperature equal to $\left(80^{\circ} \mathrm{C}\right)$, and volumetric flow rate equal to (2 LPM). The figure shows agreeable conformity between the experimental and theoretical results. Figures 11, 12, and 13 show the effect of step reduction change in the cooling water flow rate at the end of transient course along the cooling channel length on the bulk water temperature at different LOFA percentage. The figures reveal that the cooling temperature has a maximum value at the end of the channel due to the accumulated heat added to the water along the cooling channel length and getting close from it's saturation temperature with increasing the LOFA severity until reach it's saturation temperature at $75 \%$ of LOFA. It's clear that when the bulk water temperature reaches to its saturation temperature it keeps its dependency on only on the local pressure value regardless of the local heat flux profile. The figure presents agreeable conformity between the experimental and theoretical results for $25 \%, 50 \%$, and $75 \%$ of LOFA with maximum error are $1.34 \%, 2.2 \%$, and $0.5 \%$ respectively. Figures 14, 15, and 16 illustrate the effect of step reduction change transient in flow reduction on the heat source surface temperature at the end of the transient course. It's clear that the thermal hydraulic model predict the temperature distribution along the heater with good accuracy for $25 \%$ and $50 \%$ of LOFA scenario where the maximum error is $3.2 \%$, and $1.8 \%$ respectively, while the theoretical model results show less level of accuracy for $75 \%$ of LOFA scenario where the maximum error is $8.6 \%$ due to the complicity of film boiling phenomena. Figure 17, 18, and 19 represent the theoretical and experimental results of the boiling safety factor $(\mathrm{K})$ for three LOFA scenarios, $25 \%$, $50 \%$, and $75 \%$ respectively. The figures approve that the heat source kept under safe operation up to $50 \%$ of LOFA scenario due to the nucleate boiling, while the heat source experience the film boiling $(\mathrm{K}<1)$ when $75 \%$ of LOFA initiated. In $75 \%$ of LOFA the theoretical values of $\mathrm{K}$ have the same trend in comparison with experimental results but the latter refer to the occurrence of film boiling only at normalized distance equals 0.5 , where the rest of the heat source length is subject to nucleate boiling. The maximum experimental and theoretical values of the heat source temperature response for three scenarios of LOFA illustrate in figures 20,21 , and 22 . The figures reveal that the response of the theoretical model sharper than the experimental results. The nucleate boiling initiate in both $25 \%$ and $50 \%$ LOFA, while the film boiling take place at $75 \%$ of LOFA. After 55 second from initiating $75 \%$ of LOFA the experimental results show abrupt in the temperature value due to the onset of flow instability (OFI) that encounter the downward flow for the cooling fluid in low pressure and low velocity (LPLV) system. OFI take place at normalized distance equal to 0.65 away from the entrance cooling channel and that leads to partial channel dry out at that distance. Figures 23, 24, and 25 represent the theoretical and experimental results of cooling water during transient period at normalized distance equal to 0.97 . The figure reveals that the response of the theoretical temperature values much faster than the experimental. The bulk cooling temperature is kept below it's saturation temperature up to 50\% LOFA, while the bulk cooling temperature achieved it's saturation temperature during $75 \%$ of LOFA and that is occurring at normalized distance equal to 0.2 and above it. Figures 26 and 27 show surface plots for cooling water and surface temperatures measured experimentally at full power $(1920 \mathrm{~W})$ during $100 \%$ flow reduction for downward flow. Figure 28 illustrates experimental and theoretical elapsed time required 
for the bulk cooling temperature to reach its steady state versus flow reduction percentage, $25 \%, 50 \%$ and $75 \%$ respectively. The figure shows that both experimental and theoretical results have the same trend. The elapsed time increases with the flow reduction percentage when the cooling water temperature values are kept below its saturation temperature. However, when the flow reduction increases enough to bring the cooling water to its saturation the temperature the elapsed time is inversely proportional with the flow reduction. At such case the cooling fluid can increase up to its saturation temperature and can't exceed it further more as long as the dryness quality ( $\mathrm{x}$ ) is around unity. Figure 29 illustrates the experimental and theoretical elapsed time for the heat source surface temperature to reach its steady state versus flow reduction percentage, $25 \%, 50 \%$ and $75 \%$ respectively. The figure shows both experimental and theoretical results have the same trend and that its response is faster than related to cooling water. Same justification related to bulk water temperature behavior is applied here.

\section{CONCLUSION}

The results of the experimental and theoretical investigation are mainly described the thermal-hydraulic behavior of an electrical heat source cooled by forced convection ensured by water downward flow in vertical annulus during flow reduction transient conditions. As many other previous researches outputs and conclusions, such type of studies describes the safety margins of boiling crisis, necessary mitigating action required to be interfered by the engineering safety features systems, ESFS. The following conclusions could be made:

- The maximum surface temperature is located at a normalized position above the location of maximum heat flux value away from the entrance of the cooling channel and affected by many factors such as, local bulk cooling temperature, heat source surface material, local heat flux value, geometry of the cooling channel, cooling flow rate, and the type of heat transfer coefficient (convective, nucleate boiling, film boiling).

- A heat transfer process based on boiling safety factor, $\mathrm{K}$ keeps its value above unity versus flow reduction up to $50 \%$ flow reduction transient due to the effect of nucleate boiling, which depends on the local heat flux, cooling flow reduction percentage and other thermal hydraulic properties of the cooling channel. While it drops below unity at flow reduction percentage of $75 \%$ from its nominal value.

- As a result of the sharp reduction in the flow rate $(75 \%)$ accompanied with low pressure value of the cooling water inside the annular channel due the phase change in cooling water the phenomena of onset of flow instability (OFI) takes place and that leads to partial channel dry out at that location, (0.65).

- The surface temperature response is faster than that related to bulk water temperature affected by flow reduction transient as long as the cooling water temperature value is kept blow it's saturation temperature.

- At the end of $100 \%$ flow reduction transient period, the heat transfer mode inside the cooling channel is divided into two parts mainly: conduction heat transfer part below
0.5 and free convection heat transfer part above it and that is recognized by the cooling temperature and heat source surface temperature distribution.

- Installing the pressure drop element at the entrance of the cooling channel that cooled by downward flow direction has a significant effect to enhance the flow boiling stability and mitigate the backflow phenomena.

\section{NOMENCLATURE}

$\mathrm{A}_{\mathrm{f}} \quad$ Flow area of the cooling channel

$\mathrm{A}_{\mathrm{s}} \quad$ Heat source surface area

$\mathrm{C}_{\mathrm{p}} \quad$ Specific heat of constant pressure

$\mathrm{D}_{\mathrm{h}} \quad$ Hydraulic diameter

$\mathrm{d}_{\mathrm{i}} \quad$ Inner diameter of the heat source

$\mathrm{d}_{\mathrm{o}} \quad$ Inner diameter of the cooling channel

f Friction factor

F Parameter defined in equation 24

g Gravity acceleration

$\mathrm{G}_{\text {tot. }} \quad$ Total mass flux (liquid + steam)

h Heat transfer coefficient

$\mathrm{h}_{\mathrm{lg}} \quad$ Enthalpy of vaporization

$\mathrm{k}$ Thermal conductivity

$\mathrm{K} \quad$ Boiling safety factor

L Length of heat source

$\mathrm{m}^{\circ} \quad$ Mass flow rate

M Water nodal mass

$\mathrm{M}_{\mathrm{S}} \quad$ Stainless steel nodal mass

p Pressure

$\mathrm{p}_{\mathrm{i}} \quad$ Inlet pressure of cooling water

pr Prantdl number

Q Heat power

q Heat flux

Re Reynolds number

$\mathrm{S}$ Parameter defined in equation 25

$\mathrm{t}$ Time

T Temperature

$\mathrm{v}_{\mathrm{z}} \quad$ Axial velocity

$\mathrm{x} \quad$ Dryness fraction

Z Local axial position

$\mathrm{Z} \quad$ Normalized axial position

\subsection{Greek letters}

a Void fraction

$\mu$ Dynamic viscosity

$\rho$ Density

$\Phi_{\text {gtt }}$ Two phase flow friction pressure multiplier

$X_{t t} \quad$ Lockhart and Martinelli parameter

$\sigma \quad$ Surface tension

\subsection{Subscript}

$\begin{array}{ll}\text { av } & \text { Average } \\ \mathrm{b} & \text { Bulk } \\ \mathrm{B} & \text { Boiling } \\ \mathrm{c} & \text { Convective } \\ \text { conv. } & \text { Convection } \\ \mathrm{f} & \text { Film } \\ \text { FB } & \text { Film boiling } \\ \mathrm{fr} & \text { Friction pressure in single phase flow } \\ \mathrm{g} & \text { Gas } \\ \mathrm{H} & \text { Homogenous } \\ \mathrm{i} & \text { Space domain } \\ \mathrm{l} & \text { Liqued } \\ \text { mom } & \text { Mumentum }\end{array}$


NB Nucleate boiling

$\mathrm{r}$ reduced

S Heat source surface

st Steady state

stat Static pressure for single phase flow

STAT Static pressure for two phase flow

sp Single phase

$\mathrm{t} \quad$ time domain

tot. Total

tp Two phase

v Vapor

\section{ACKNOELEDGMENTS}

First of all thanks to Allah the most merciful, the most kind to give me the power and the patience to accomplish this work. I would like to express my profound gratitude and appreciation to my supervisor "Assist. Prof. Dr. Akram W. Ahmed "for his kind patronage, excellent scientific advice and motivation support throughout the steps of this work. It has been a privilege to have worked with him. I'm sure without his guidance; this work would not have taken this final shape. Thanks are extended to my colleagues, Engineer Mohammed Al-Azawy and Engineer Aws Al-Saffar for their assistance and help during conducting the experimental test. My deep gratitude is towards my parents, my brother, my sister for their incessant prayers, more supports, guidance, encouragement and patience during my studies. They are the source of power, inspiration and confidence in me.

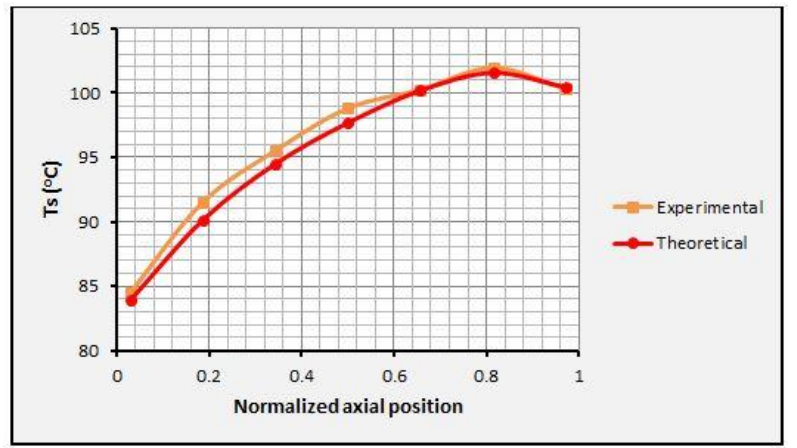

Figure (8): Experimental and theoretical heat source surface temperature versus normalized distance during steady state condition

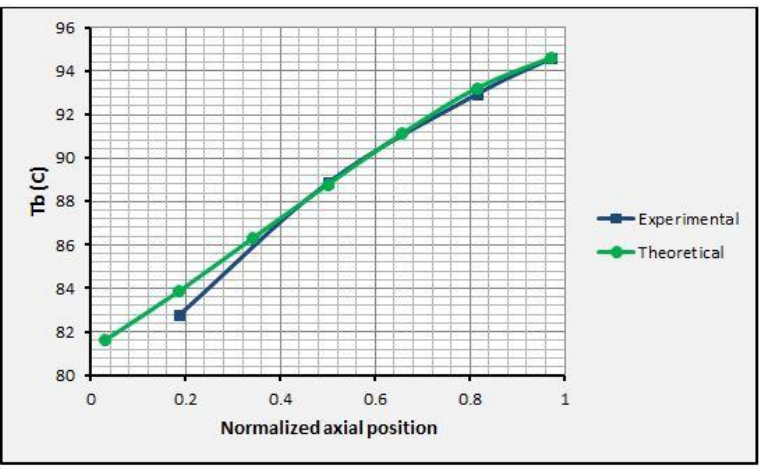

Figure (9): Experimental and theoretical bulk water temperature versus normalized distance during steady state condition.

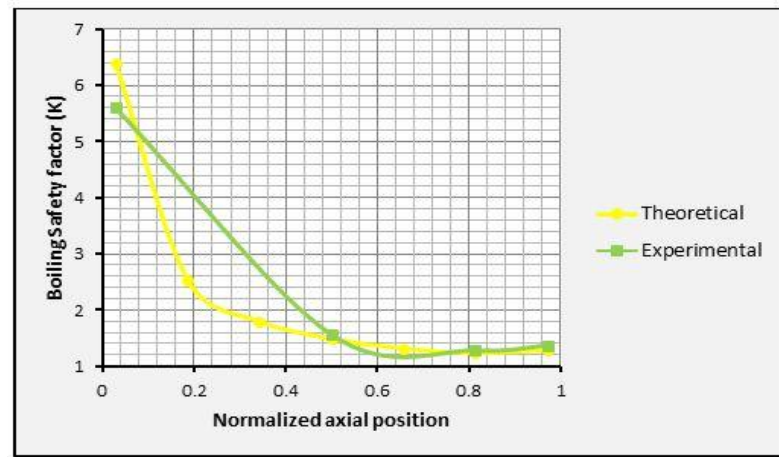

Figure (10): Experimental and theoretical boiling safety factor versus normalized distance during steady state condition.

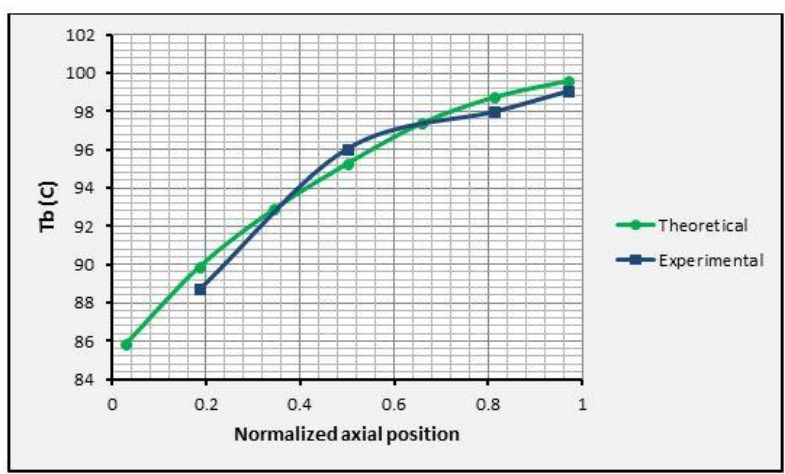

Figure (11): Experimental and theoretical bulk water temperature distribution versus normalized length during $25 \%$ LOFA at the end of the transient.

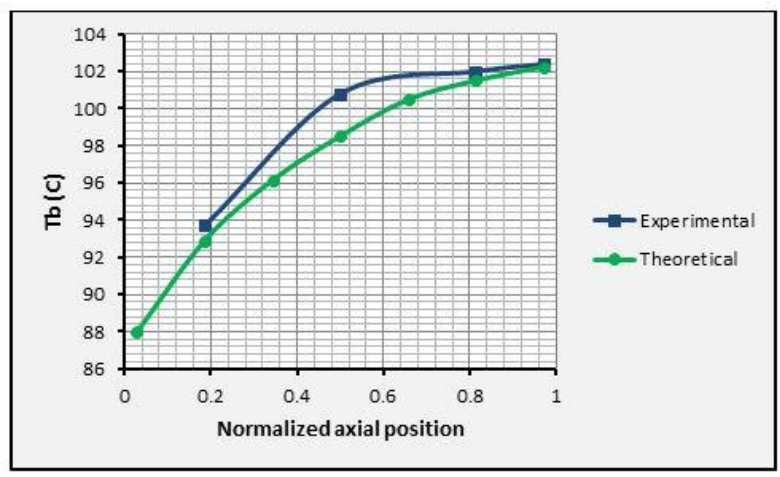

Figure (12): Experimental and theoretical bulk water temperature distribution during 50\% LOFA at the end of the transient

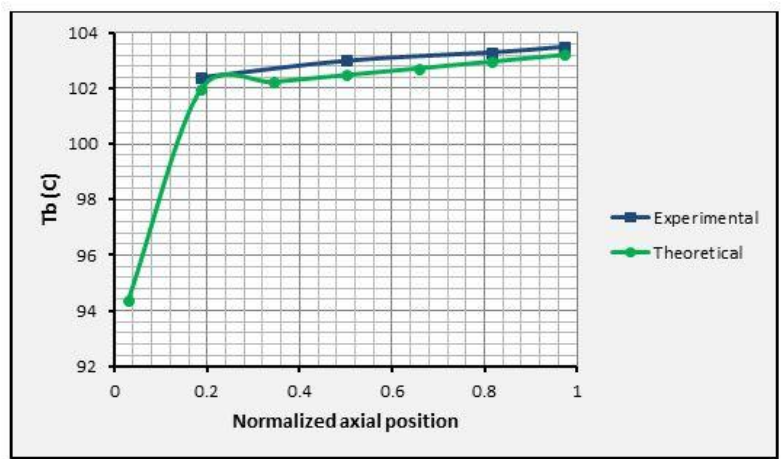

Figure (13): Experimental and theoretical bulk water temperature distribution versus normalized length during $75 \%$ LOFA at the end of the transient 


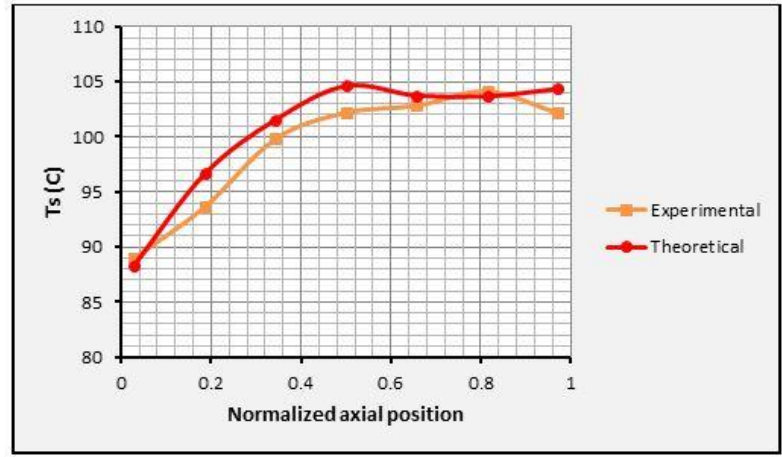

Figure (14): Experimental and theoretical heat source surface temperature versus normalized length during $\mathbf{2 5 \%}$ of LOFA at the end of the transient

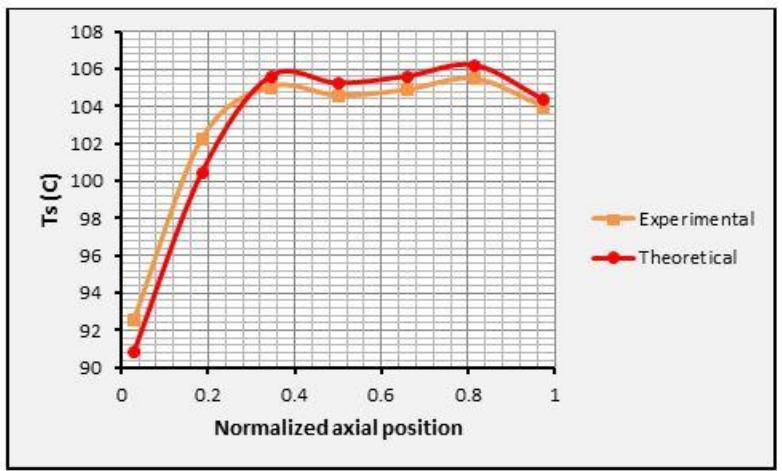

Figure (15): Experimental and theoretical heat source surface temperature versus normalized length during $\mathbf{5 0 \%}$ of LOFA at the end of the transient.

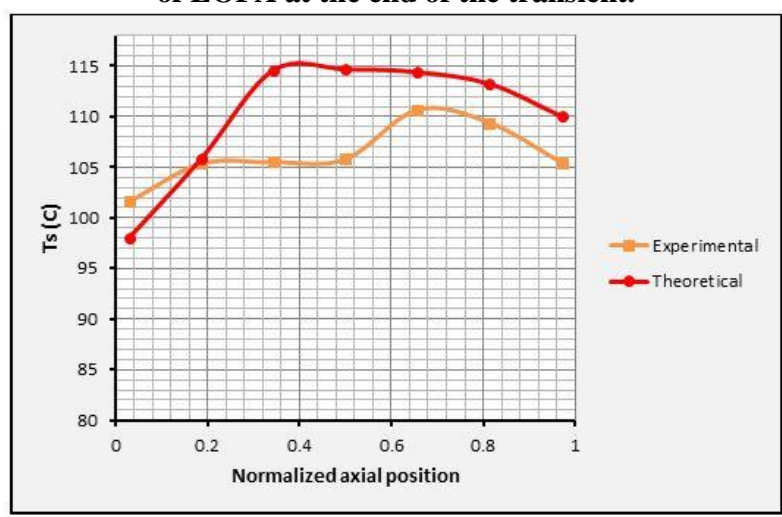

Figure (16): Experimental and theoretical heat source surface temperature distribution during $75 \%$ of LOFA at the end of the transient

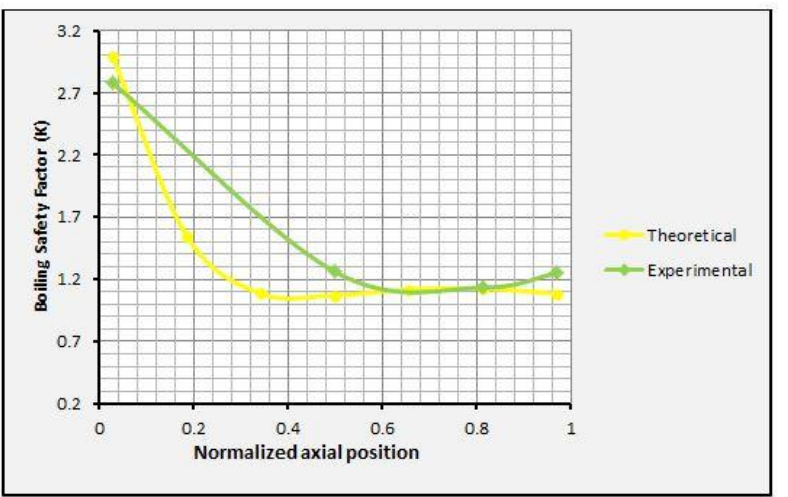

Figure (17): Experimental and theoretical boiling safety factor distribution during $25 \%$ of LOFA at the end of the transient.

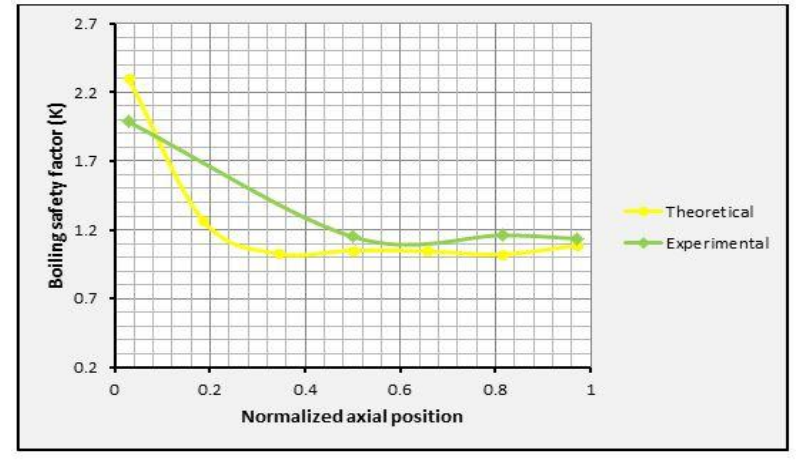

Figure (18): Experimental and theoretical boiling safety factor distribution during $50 \%$ of LOFA at the end of the transient.

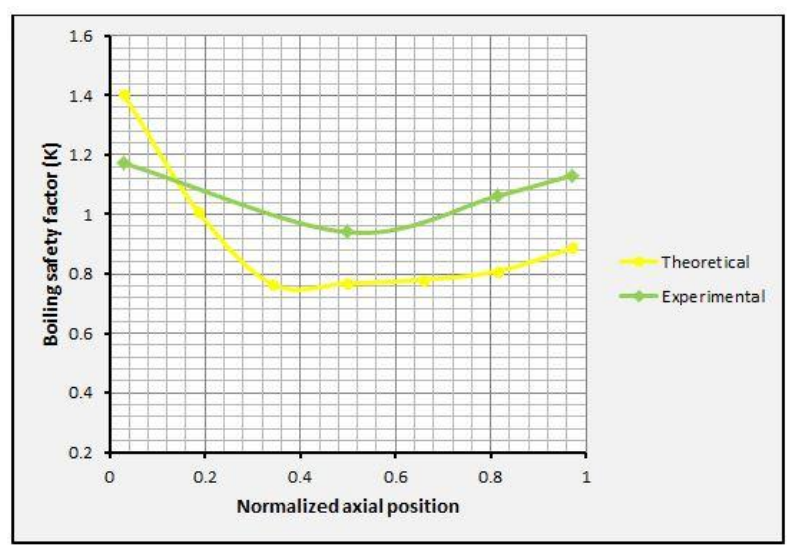

Figure (19): Experimental and theoretical boiling safety factor distribution during $75 \%$ of LOFA at the end of the transient.

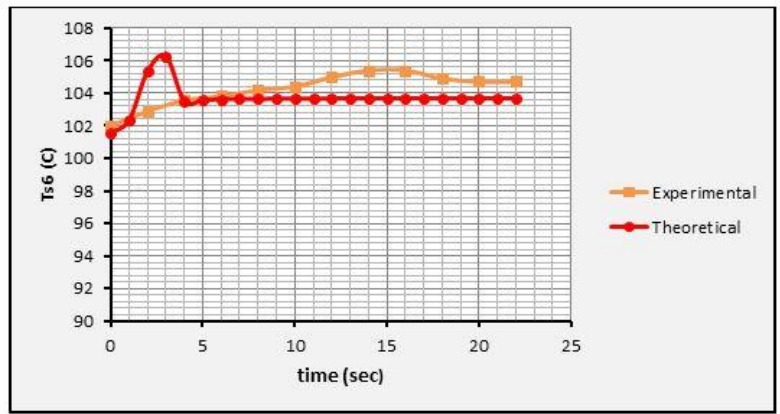

Figure (20): Theoretical and experimental surface temperature versus time at normalized distance, $(0.81)$ during $25 \%$ flow reduction transient.

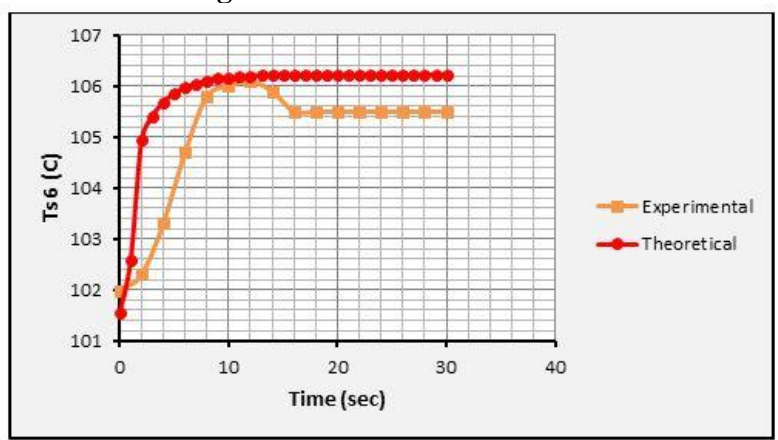

Figure (21): Theoretical and experimental surface temperature versus time at normalized distance, $(0.81)$ during $50 \%$ flow reduction transient. 


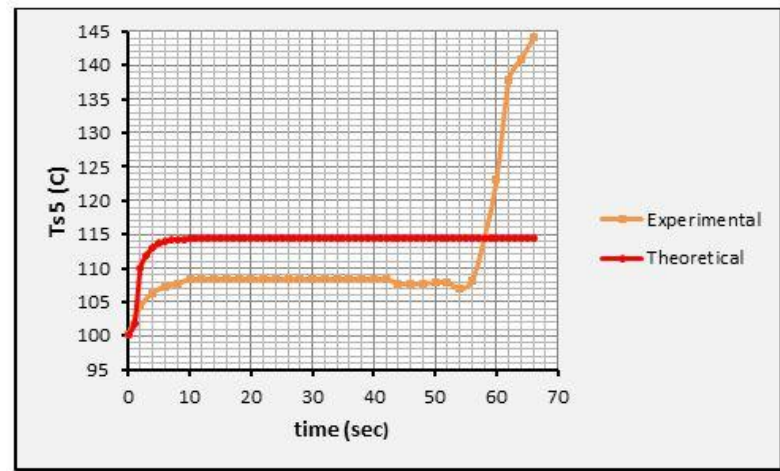

Figure (22): Theoretical and experimental surface temperature versus time at normalized distance, $(0.81)$ during $50 \%$ flow reduction transient.

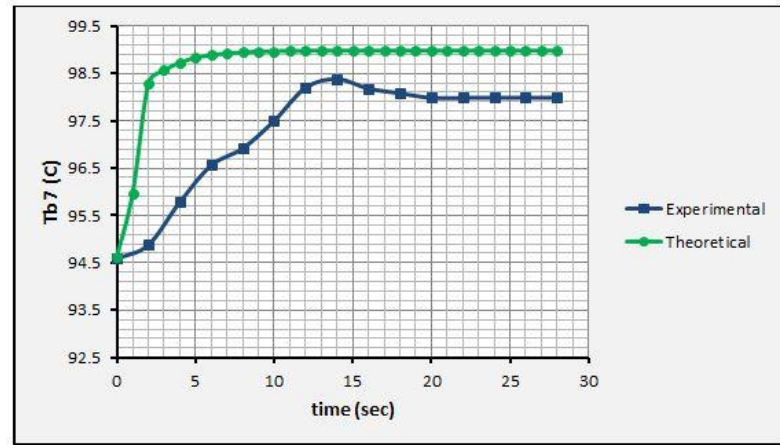

Figure (23): Theoretical and experimental bulk water temperature versus time at normalized distance, $(0.97)$ during $25 \%$ flow reduction transient.

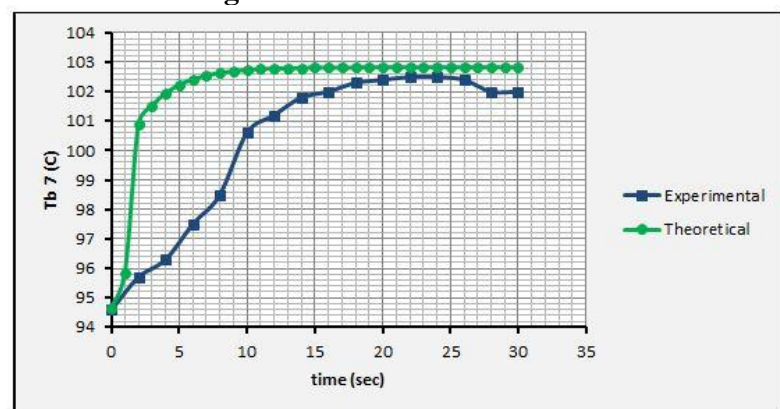

Figure (24): Theoretical and experimental bulk water temperature versus time at normalized distance, $(0.97)$ during $50 \%$ flow reduction transient.

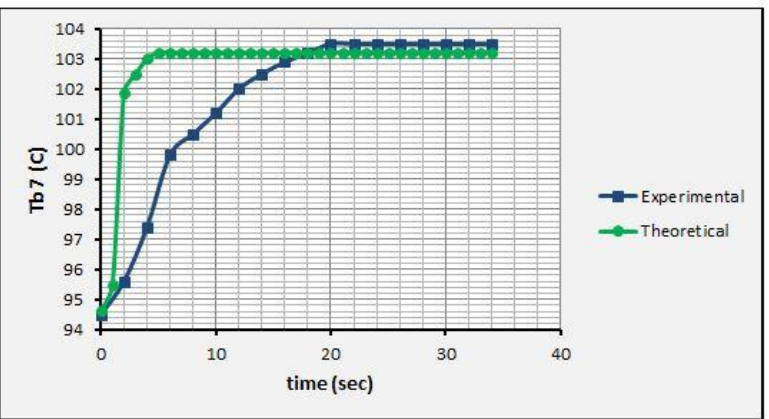

Figure (25): Theoretical and experimental bulk water temperature versus time at normalized distance, $(0.97)$ during $75 \%$ flow reduction.

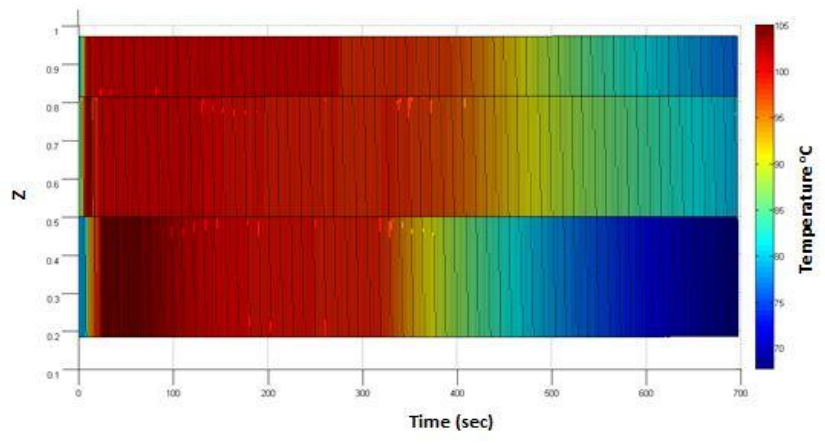

Figure (26): Cooling water temperature versus time and length during $100 \%$ flow reduction

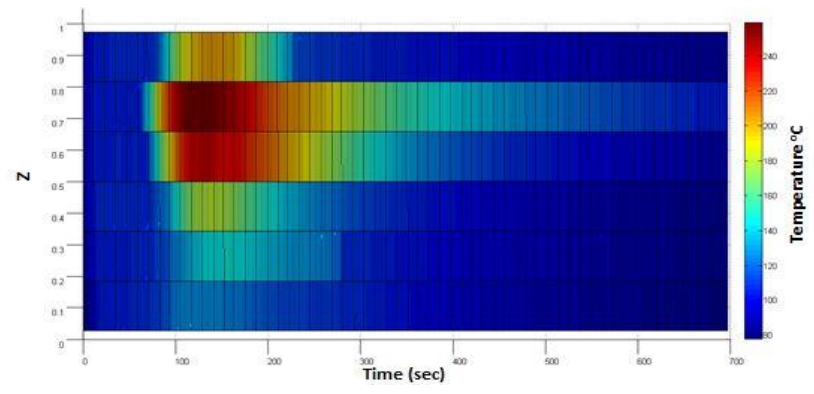

Figure (27): Surface temperature versus time and length during $100 \%$ flow reduction.

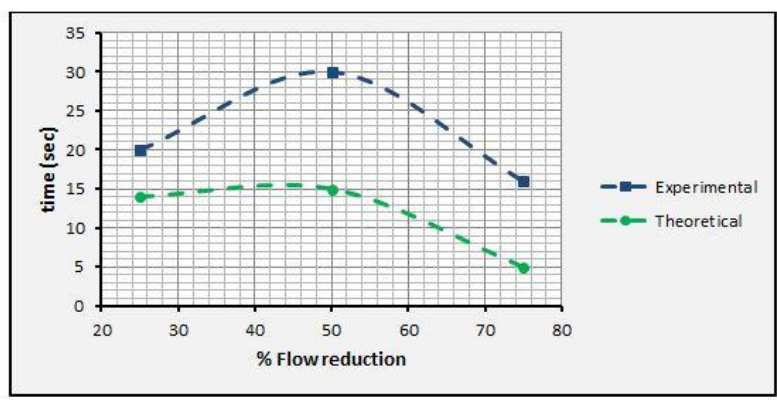

Figure (28): Experimental and theoretical elapsed time for bulk cooling water temperature to reach its steady state versus flow reduction percentage.

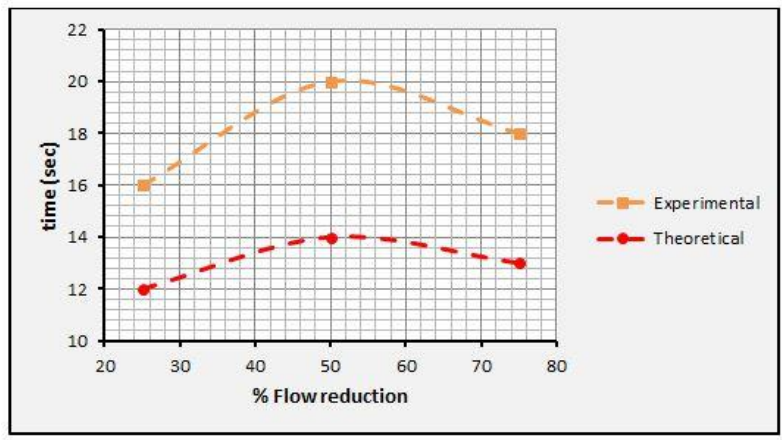

Figure (29): Experimental and theoretical elapsed time for surface temperature to reach its steady state versus flow reduction percentage. 


\section{REFERENCES}

[1] Ahmed Mohammed El-Messiry. (2000) " Accident of loss of flow for the ETTR-2 reactor: dramatic analysis" ORIGNAL PAPER, NUKLEONIKA, Vol. 45, No. 4, PP. 229-233

[2] Qing Lu, Suizheng Qiu, G.H. Su. (2009) "Flow blockage analysis of a channel in a typical material test reactor core" Journal of Nuclear Engineering and Design, Vol. 239 , PP. 45-50.

[3] Hainoun, N.Ghazi, B. Mansour Abdul-Moaiz. (2010) "Safety analysis of the IAEA reference research reactor during loss of flow accident using the code MERSAT" Journal of Nuclear Engineering and Design, Vol. 240, PP.1132-1138.

[4] Hong Gao, Feng Gao, Xianchao Zhao, Jie Chen, Xuewu Cao. (2011) "Transient flow analysis in reactor coolant pump systems during flow coastdown period" Journal of Nuclear Engineering and Design, Vol. 241, PP.509-514.

[5] A.D. Vasiliev, A.E Kisselev, V.F. Strihov. (2012) "Application of thermal hydraulic and severe accident code SOCRAT/V2 to bottom water reflood experiment PARAMETER-SF4" Journal of Nuclear Engineering and Design, Vol. 246, PP.175-184.
[6] A.W.Ezzat and H.M.Taki. (1988) "Final safety report for $14^{\text {th }}$ Tammuz $5000 \mathrm{KW}$ reactor", INC, Iraq nuclear commission under the supervision of IAEA, paragraph 5.4 .

[7] Frank Krieth, Raj M. Manglik, and Mark S. Bohn. (2011) "PRICIPLIES OF HEAT TRANSFER" Cengage Learning Inc. , $7^{\text {th }}$ Edition.

[8] Latif M. Jiji. (2006) "HEAT CONVECTION" Sipringer, $1^{\text {st }}$ Edition.

[9] M.M.El.Wakil. (1962) "Nuclear Power Engineering " McGraw-Hill Book Company, New York.

[10] Michael J. Moran, Howard N. Shapiro, Daisie D. Boettner, and Margaret B. Bailey.(2011)"Fundamentals of Engineering Thermodynamics "JHON WILY and SONS Inc., $7^{\text {th }}$ Edition.

[11] Fox and McDonald's.(2011) "Introduction to Fluid Mechanics"JHON WILY and SONS, Inc., $8^{\text {th }}$ Edition.

[12] D.Butterworth and G.F. Hewitt. (1977)" TWO-PHASE FLOW AND HEAT TRANSFER" Harwll Series, OXFORD UNIVERSITY PRESS.

[13] Holman, J.P. (2001) "Experimental Methods for Engineers" McGraw-Hill Inc., $7^{\text {th }}$ Edition. 